\title{
Olanzapine Increases Grey and White Matter Volumes in the Caudate Nucleus of Patients with Schizophrenia
}

\author{
Gaku Okugawa Kenji Nobuhara Katsunori Takase Yukiko Saito \\ Masafumi Yoshimura Toshihiko Kinoshita \\ Department of Neuropsychiatry, Kansai Medical University, Osaka, Japan
}

\section{Key Words}

Caudate nucleus • Magnetic resonance imaging, schizophrenia $\cdot$ Olanzapine $\cdot$ Schizophrenia $\cdot$ White matter

\begin{abstract}
There are inconsistent reports regarding the caudate nucleus volume in patients with schizophrenia compared with healthy subjects. The reason for this is that neuroleptic medication may affect the volume of the caudate nucleus in schizophrenic patients. To clarify which antipsychotic medication changes the volume of the caudate nucleus in patients with schizophrenia, we measured the volumes of grey and white matter in the caudate nucleus of schizophrenic patients. Ten patients with schizophrenia were examined twice by magnetic resonance imaging (MRI) to measure the grey and white matter volumes in the caudate nucleus. After the first MRI examination, all the patients were treated with olanzapine. The clinical responses were evaluated by the positive and negative rating scale. When the symptoms improved, the patients were examined by a second MRI scan. Ten healthy control subjects also underwent MRI. The schizophrenic patients had reduced volumes of grey and white matter in the caudate nucleus compared to the healthy con-
\end{abstract}

trol subjects. The volumes of grey and white matter in the caudate nucleus of the schizophrenic patients increased after treatment with olanzapine. These findings suggest that treatment with olanzapine may increase the grey and white matter volumes in the caudate nucleus in patients with schizophrenia.

Copyright $\odot 2007$ S. Karger AG, Basel

\section{Introduction}

A previous volumetric magnetic resonance imaging (MRI) study from our research group reported that schizophrenic patients had a smaller volume of white matter, but the same volume of grey matter, in the caudate nucleus compared to healthy subjects [1]. In addition, the volume of the caudate nucleus white matter in patients with schizophrenia was correlated with the total amount of antipsychotics administered during the previous year. However, that study was cross-sectional rather than longitudinal, and the schizophrenic patients received various kinds of antipsychotics.

There are several previous MRI studies regarding tissue volume using the segmentation program. Tamagaki

\section{KARGER \\ Fax +4161306 1234 \\ E-Mail karger@karger.ch}

www.karger.com
(C) 2007 S. Karger AG, Basel

0302-282X/07/0551-0043\$23.50/0

Accessible online at:

www.karger.com/nps
Gaku Okugawa, MD, PhD

Department of Neuropsychiatry, Kansai Medical University

10-15 Fumizonocho Moriguchi

Osaka 570-8506 (Japan)

Tel. +81 66992 1001, Fax +81 66995 2669, E-Mail okugawa@takii.kmu.ac.jp 
et al. [2] reported that schizophrenic patients had a reduced white matter volume in the caudate nucleus compared to healthy subjects. An increased volume of the caudate nucleus was found in patients with first-episode schizophrenia [3]. There was no significant difference in caudate nucleus volume between neuroleptic-naïve schizophrenic patients and healthy subjects [4]. Neuroleptic exposure was associated with caudate nucleus volume changes over time in men with schizophrenia [5]. Typical antipsychotics increased the volume of the caudate nucleus, but did not change the cerebral volume, in schizophrenic patients [6]. Treatment with antipsychotics increased the volume of the caudate nucleus and improved cognitive deficits in patients with schizophrenia [7]. However, the volume changes in the grey and white matter in the caudate nucleus after antipsychotic administration are not well known.

In the present study, we compared the grey and white matter volumes in the caudate nucleus between pretreatment schizophrenic patients and healthy subjects. To clarify whether antipsychotic drugs induce changes in the volume of the caudate nucleus, we investigated the grey and white matter volumes in the caudate nucleus of patients with schizophrenia before and after pharmacotherapy with olanzapine using MRI.

\section{Methods}

The protocol was approved by the Institutional Review Board at Kansai Medical University. The patients gave written informed consent before participating in the study.

\section{Subjects}

The initial subjects were twelve patients (seven men and five women) with schizophrenia, who fulfilled the DSM-IV criteria [8]. Two male patients subsequently dropped out of the study for unknown reasons. Five patients were paranoid type, three were disorganized type and the remaining two were catatonic type. Eight were outpatients and two were inpatients. From interviews at each visit during the investigation, their compliances for drug intake were good. Ten healthy individuals (five men and five women) without any axis I disorders according to the Structured Clinical Interview for DSM-III-R were recruited at the Department of Neuropsychiatry, Kansai Medical University Hospital. At the first investigation, the patients with schizophrenia had not received any medication for one year. All the patients received olanzapine for treatment of schizophrenia after the first MRI scan. Two patients also received brotizolam and flunitrazepam for sleep disturbance. The criterion for undertaking the second MRI scan was a reduction in the positive and negative rating scores (PANSS) to less than $50 \%$ relative to the baseline values. All the control subjects were found to be healthy according to physical examination and blood and urinary tests. Exclusion criteria for the healthy subjects were a history of alcohol or drug addiction, head trauma with loss of consciousness for more than five min or a history of severe somatic disorder.

\section{MR Volumetry}

The subjects were examined with a 1.5-tesla GE Signa system at the Department of Radiology, Kansai Medical University Hospital. $\mathrm{T}_{1}$-weighted images using a spoiled GRASS sequence were acquired with the following parameters: $1.5-\mathrm{mm}$ coronal slices; no gap; $35^{\circ}$ flip angle; TR $=24 \mathrm{~ms}$; TE $=6.0 \mathrm{~ms} ; 1 \mathrm{NEX}$; FOV $=24$ $\mathrm{cm}$; acquisition matrix $=256 \times 192 . \mathrm{T}_{2}$-weighted images were acquired with the following parameters: $3.0-\mathrm{mm}$ coronal slices; no gap; TE $=84 \mathrm{~ms} ; \mathrm{TR}=6,000 \mathrm{~ms} ; 1 \mathrm{NEX}$; FOV $=24 \mathrm{~cm}$; acquisition matrix $=256 \times 192$.

\section{Automated Segmentation}

MR data analysis was performed using the BRAINS software $[9,10]$. The reliability and reproducibility of the segmentation procedure were ascertained previously [10-12].

\section{Tracing of the Caudate Nucleus}

We analyzed the caudate nucleus and intracranial space. The details of the delineation of the caudate nucleus were established and described in a previous study [1]. The caudate nucleus was delineated using segmented coronal slices. The anterior and posterior boundaries of the caudate nucleus were determined on the slice that demonstrated the caudate nucleus structure and the most anterior part of the pons, respectively. The medial and lateral boundaries were the edge of the lateral ventricle and internal capsule, respectively. The tissue volumes of the caudate nucleus on the right and left sides were measured. Since the caudate nucleus is one of the smaller structures in the brain, the individual tissue volumes from the right and left sides were combined in the calculations. The quantitative analysis of all procedures was performed in a blinded manner with regard to the subjects. To correct for individual differences in head size, we calculated relative volumes $(1,000 \times$ absolute volume/intracranial volume).

\section{Clinical Evaluation}

In the schizophrenic patients, the PANSS scores were evaluated at the times of the first and second MRI scans. The interviews were conducted by an experienced psychiatrist who was well trained in the administration of the instrument. The total score of the positive and negative symptoms was used for statistical analysis of differences before and after treatment with olanzapine. The mean dose (milligrams/day) and mean total amount (milligrams) of olanzapine were calculated between the first and second scans.

\section{Statistical Analysis}

The unpaired t test was used to compare relative volumes of the caudate nucleus of the schizophrenic patients with those of the healthy subjects. The paired t test was applied to compare relative volumes of the caudate nucleus and PANSS score at the first scan with those at the second scan. Differences were considered to be statistically significant at $\mathrm{p}<0.01$. 
Table 1. Characteristics of the schizophrenic patients and healthy subjects

\begin{tabular}{llllll}
\hline & Cases & $\begin{array}{l}\text { Age } \\
\text { years }\end{array}$ & $\begin{array}{l}\text { Age at } \\
\text { onset } \\
\text { years }\end{array}$ & $\begin{array}{l}\text { Dose of } \\
\text { olanzapine } \\
\text { mg/day }\end{array}$ & $\begin{array}{l}\text { Duration of } \\
\text { olanzapine } \\
\text { medication } \\
\text { days }\end{array}$ \\
\hline $\begin{array}{l}\text { Schizophrenic patients } \\
\text { Healthy subjects }\end{array}$ & $10(5 / 5)$ & $31.6 \pm 6.3$ & $28.1 \pm 4.8$ & $14.3 \pm 4.0$ & $186 \pm 60$ \\
\hline
\end{tabular}

Values are means \pm SD. Figures in parentheses represent men/women.
Table 2. Relative volumes of grey and white matter in the caudate nucleus and intracranial space in ten pretreatment and ten posttreatment schizophrenic patients and ten healthy subjects

\begin{tabular}{lccc}
\hline & Patients & $\begin{array}{l}\text { Healthy } \\
\text { subjects }\end{array}$ & p value \\
& & & \\
\hline $\begin{array}{l}\text { Pretreatment schizophrenic patients versus healthy subjects } \\
\text { Volumes in the caudate nucleus, ml }\end{array}$ & $2.41 \pm 0.34$ & $2.80 \pm 0.25$ & 0.01 \\
$\quad$ Grey matter & $0.60 \pm 0.16$ & $0.89 \pm 0.19$ & 0.002 \\
$\quad$ White matter & $1,499 \pm 78$ & $1,473 \pm 168$ & $\mathrm{NS}$ \\
Intracranial volume, ml & $2.54 \pm 0.34$ & $2.80 \pm 0.25$ & $\mathrm{~N}$ \\
\hline Posttreatment schizophrenic patients versus healthy subjects & & 0.005 \\
Volumes in the caudate nucleus, ml & $0.63 \pm 0.16$ & $0.89 \pm 0.19$ & $\mathrm{NS}$ \\
$\quad$ Grey matter & $1,499 \pm 78$ & $1,473 \pm 168$ & \\
$\quad$ White matter & & \\
Intracranial volume, ml & & \\
\hline \multicolumn{2}{l}{ p value: Student's t test. NS = Not significant. } \\
\hline
\end{tabular}

\section{Results}

\section{Subject Characteristics}

Table 1 shows the data for age at the first investigation, age at onset, dose of olanzapine and duration of olanzapine medication. The mean time period between the first and second scans was $186 \pm 60$ days. The mean total amount of olanzapine administered to the schizophrenic patients was $2,517 \pm 601 \mathrm{mg}$. The mean illness duration was $4.7 \pm$ 2.7 years. The mean PANSS scores of the first and second scans were $105 \pm 12$ and $42 \pm 6$, respectively.

\section{Volume Measurement}

Pretreatment schizophrenic patients had significantly smaller volumes of grey matter $(\mathrm{p}=0.01)$ and white matter $(p=0.002)$ in the caudate nucleus than healthy subjects. Posttreatment schizophrenic patients had significantly smaller volumes of white matter in the caudate nucleus than healthy subjects $(\mathrm{p}=0.005)$ (table 2$)$.

There was a significant difference in the PANSS of the ten patients between the first and second investigations.
No significant difference was found in the intracranial volumes between the first and second scans.

Posttreatment schizophrenic patients had significantly larger volumes of grey matter $(p<0.001)$ and white matter $(\mathrm{p}=0.002)$ in the caudate nucleus than pretreatment schizophrenic patients.

\section{Discussion}

In the present study, schizophrenic patients had smaller volumes of grey and white matter in the caudate nucleus compared to healthy subjects. After treatment of the schizophrenic patients with olanzapine, the volumes of grey and white matter in the caudate nucleus increased. There was no significant difference in the grey matter volumes in the caudate nucleus between schizophrenic patients treated with olanzapine and healthy subjects. We did not find any remarkable volume changes in the intracranial tissue volumes in the schizophrenic patients. The PANSS scores of the ten 
schizophrenic patients were significantly improved by treatment with olanzapine.

The atypical antipsychotic agents olanzapine and clozapine were reported to upregulate brain-derived neurotrophic factor mRNA expression in the rat brain [13]. Since nerve growth factor and brain-derived neurotrophic factor increase neuronal cell size, stimulate synaptic plasticity and subsequently increase myelinated axons in the brain, olanzapine treatment may increase the grey and white matter volumes in the caudate nucleus in patients with schizophrenia.

Since the caudate nucleus plays an important role in cognitive function, it has been considered that impairment of the caudate nucleus is associated with psychotic symptoms in patients with schizophrenia. The degree of reduction in caudate nucleus volume was significantly related to the extents of improvement in the positive and negative symptoms in patients with schizophrenia [14]. Increases in the caudate nucleus grey matter and white matter volumes were found between first and second scans in our schizophrenic patients.
The present results support the view that treatment with olanzapine may increase the grey and white matter volumes in the caudate nucleus of patients with schizophrenia.

A limitation of the study is the small number of subjects. We need to accumulate additional imaging studies in a larger sample of schizophrenic patients treated with olanzapine to clarify the relationship between the caudate nucleus volume changes and the improvement in psychiatric symptoms due to schizophrenia.

\section{Acknowledgements}

We thank Dr. Ingrid Agartz, Department of Clinical Neuroscience, Psychiatry Section, Karolinska Institute, for valuable discussions and Dr. Nancy C. Andreasen and Vincent Magnotta, Mental Health Clinical Research Center, University of Iowa College of Medicine and Hospital and Clinics, Iowa, for excellent support during the implementation of BRAINS 2. This work was supported by grants from the Ministry of Education, Science and Culture of Japan (17790826) and Eli Lilly Japan.

\section{References}

1 Takase K, Tamagaki C, Okugawa G, Nobuhara K, Minami T, Sugimoto T, et al: Reduced white matter volume of the caudate nucleus in patients with schizophrenia. Neuropsychobiology 2004;50:296-300.

2 Tamagaki C, Sedvall GC, Jonsson EG, Okugawa G, Hall H, Pauli S, Agartz I: Altered white matter/grey matter proportions in the striatum of patients with schizophrenia: a volumetric MRI study. Am J Psychiatry 2005;162:2315-2321.

-3 Chakos MH, Lieberman JA, Bilder RM, Borenstein $\mathrm{M}$, Lerner $\mathrm{G}$, Begerts $\mathrm{B}$, Wi H, Kinon $\mathrm{B}$, Ashtari M: Increase in caudate nuclei volumes of first-episode schizophrenic patients taking antipsychotic drugs. Am J Psychiatry 1994;151:1430-1436.

-4 Gur RE, Many V, Mozley D, Swanson C, Bilker W, Gur RC: Subcortical MRI volumes in neuroleptic-naïve and treated patients with schizophrenia. Am J Psychiatry 1998; 155:1711-1717.

$\checkmark 5$ Heitmiller DR, Nopoulos PC, Andreasen NC: Changes in caudate volume after exposure to atypical neuroleptics in patients with schizophrenia may be sex-dependent. Schizophr Res 2004;66:137-142.
-6 Keshavan MS, Bagwell WW, Haas GL, Sweeney JA, Schooler NR, Pettegrew JW: Changes in caudate volume with neuroleptic treatment. Lancet 1994;344:1434.

7 DeLisi LE, Sakuma M, Tew W, Kushner M, Hoff AL, Grimson R: Schizophrenia as a chronic active brain process: a study of progressive brain structural change subsequent to the onset of schizophrenia. Psychiatry Res 1997;74:129-140.

8 American Psychiatric Association: Diagnostic and Statistical Manual of Mental Disorders, ed 4. Washington, American Psychiatric Association Press, 1994.

\9 Andreasen NC, Cizadlo T, Harris G, Swayze V 2nd, O'Leary DS, Cohen G, Ehrhardt J, Yuh WT: Voxel processing techniques for the antemortem study of neuroanatomy and neuropathology using magnetic resonance imaging. J Neuropsychiatry Clin Neurosci 1993;5:121-130.

$>10$ Harris G, Andreasen NC, Cizadlo T, Bailey JM, Bockholt HJ, Magnotta VA, Arndt S: Improving tissue classification in MRI: a threedimensional multispectral discriminant analysis method with automated training class selection. J Comput Assist Tomogr 1999;23:144-154.
11 Agartz I, Okugawa G, Nordstrom M, Greitz D, Magnotta V, Sedvall G: Reliability and reproducibility of brain tissue volumetry from segmented MR scans. Eur Arch Psychiatry Clin Neurosci 2001;251:255-261.

12 Okugawa G, Takase K, Nobuhara K, Yoshida T, Minami T, Tamagaki C, Magnotta VA, Andreasen NC, Kinoshita T: Inter- and intraoperator reliability of brain tissue measures using magnetic resonance imaging. Eur Arch Psychiatry Clin Neurosci 2003; 253:301-306.

13 Bai O, Chlan-Fourney J, Bowen R, Keegan D, Li XM: Expression of brain-derived neurotrophic factor mRNA in rat hippocampus after treatment with antipsychotic drugs. J Neurosci Res 2003;71:127-131.

$\rightarrow 14$ Scheepers FE, Gispen de Wied CC, Hulshoff Pol HE, Kahn RS: Effect of clozapine on caudate nucleus volume in relation to symptoms of schizophrenia. Am J Psychiatry 2001;158: 644-646. 